\title{
PENGARUH TERAPI SENTUHAN TERHADAP SUHU TUBUH PADA BAYI PREMATUR
}

\author{
Neneng Fitria Ningsih \\ Dosen FIK Universitas Pahlawan Tuanku Tambusai, Riau, Indonesia
}

\begin{abstract}
ABSTRAK
World Health Organization (WHO) menyebutkan bahwa terdapat satu dari sepuluh kelahiran adalah bayi premature.Lebih dari 15 juta bayi lahir dalam keadaan premature.Prematuritas ini dapat menyebabkan angka kematian perinatal yang cukup tinggi.Salah satu penangan bayi premature adalah memberikan terapi sentuhan.Jenis penelitian adalahquasi experiment.Desain penelitian ini menggunakan purposive sampling. Populasi penelitian ini adalah seluruh bayi premature yang di rawat diruangan perinatologi RSUD Bangkinang Periode Januari-Juni 2017.Sampel dalam penelitian ini berjumlah 30 responden.Alat ukur dengan Tabel Check List. Analisis data yang digunakan adalah univariatdan bivariat. Hasil penelitian didapatkan ada pengaruh terapi sentuhan terhadap suhu tubuh pada bayi premature di RSUD Bangkinang dengan nilai $\mathrm{P}_{\text {value }}=0,000$, dengan demikian berarti $\mathrm{P}_{\text {value }}<\alpha(0,05)$. Diharapkan tenaga kesehatan meningkatkan pengetahuan yang up to date khusunya tentang perawatan bayi premature dan bisa menerapkan terapi sentuhan untuk membantu meningkatkan suhu tubuh bayi premature.
\end{abstract}

Daftar Bacaan : $16(2003-2014)$

Kata Kunci : : Terapi sentuhan, Bayi prematur

\section{PENDAHULUAN}

Angka kematian dan kesakitan bayi dipengaruhi berbagai factor, salah satu factor yang mempengaruhi adalah keadaan pada waktu bayi tersebut dilahirkan.Data yang ada di Indonesia menyebutkan bahwa setiap tahun diperkirakan bayi lahir sekitar 350.000 bayi prematur atau berat badan lahir rendah. Pola penyakit penyebab kematian menunjukkan bahwa proporsi penyebab kematian neonatal kelompok umur 0-7 hari tertinggi adalah prematur dan berat badan lahir rendah (35\%), kemudian asfiksia lahir $(33,6 \%)$ (Survey Demografi dan Kesehatan Indonesia 2007).
Bayi prematur adalah bayi yang dilahirkan dengan masa gestasi kurang dari 37 minggu dan dengan berat badan yang rendah (Wahley \& Wong, 2004).Pada bayi prematur kematangan semua organ belum tercapai dengan baik.keadaan ini menyebabkan perawatan pada bayi prematur harus dilakukan dengan baik terutama menjaga kestabilan suhu dan frekuensi denyut jantung. Apabila semua system diperhatikan dengan baik maka bayi dapat bertahan dan tumbuh kembang dengan baik. menurut Whaley dan Wong (2004), bayi yang dilahirkan dengan berat badan kurang dari 2500 gram duapuluh kali lebih besar mengalami kematian di bulan pertama kehidupannya, dibandingkan dengan 
bayi yang lahir dengan berat badan yang normal. Resiko akan meningkat lebih tinggi pada bayi yang dilahirkan dengan berat badan kurang dari 1500 gram.

Bayi prematur diharuskan dirawat di incubator, karena bayi dengan berat badan yang rendah belum mempunyai kemampuan untuk beradaptasi dengan suhu lingkungan.Incubator berguna untuk menjaga suhu bayi supaya tetap stabil, akibat system pengaturan suhu dalam tubuh bayi prematur belum sempurna, yang dapat membahayakan kondisi kesehatannya (Mochtar, 2004).

Asuhan keperawatan pada bayi prematur adalah dapat membantu bayi tersebut untuk dapat beradaptasi sehingga akan dicapai homeostasis. Perawat di ruang perinatology harus dapat melakukan perawatan dengan baik yang memperhatikan konservasi energy bayi dan mencari metoda perawatan pada bayi prematur sesuai dengan perkembangan yang ada saat sekarang ini, salah satunya adalah memberikan terapi sentuhan pada bayi prematur.Terapi sentuhan merupakan terapi yang sudah dikenal sejak dulu.Banyak penelitian tentang terapi sentuhan pada bayi ini, diantaranya membuktikan bahwa terapi sentuhan pada bayi dapat meningkatkan pertumbuhan berat badan, meningkatkan suhu dan membuat bayi lebih nyaman dan lebih tenang pada saat tidur (Dieter et al., 2003).

\section{Metode Penelitian}

Jenis penelitian ini adalah eksperimen, dengan design quasi experimen dengan rancangan one group pretest-posttest. Rancangan ini juga tidak ada kelompok pembanding (control), design yang dilakukan dengan cara melakukan observasi sebanyak dua kali yaitu sebelum dan sesudah dilakukan tindakan
(Notoatmojo,2010) dilakukan di ruang perinatologi RSUD Bangkinang

\section{Populasi dan Sampel}

Populasi dalam penelitian ini adalah semua bayi prematur yang dirawat di ruang perinatologi RSUD Bangkinang, Kabupaten Kampar, Provinsi Riau. Jumlah bayi prematur tahun 2017periode Januari sampai dengan Maret tercatat sebanyak 27 kelahiran bayi premature Sampel pada penelitian ini adalah bayi prematur yang dirawat di ruang perinatologi RSUD Bangkinang

\section{Analisa Univariat}

a. Distribusi Frekuensi Bayi Prematur yang Dirawat di ruangan Perinatologi di RSUD Bangkinang Berdasarkan Usia Gestasi, Usia, dan Berat Badan

\begin{tabular}{cccccc}
\hline No & Variabel & Mean & SD & $\begin{array}{c}\text { Minimal } \\
\text { Maksimal }\end{array}$ & $\begin{array}{c}\text { CI } \\
\mathbf{9 5 \%}\end{array}$ \\
\hline 1 & Usia & 31,70 & 2,25 & $28-35$ & $30,86-$ \\
& $\begin{array}{c}\text { Gestasi } \\
\text { (mgg)) }\end{array}$ & & & & 32,54 \\
& Usia & 10,87 & 4,22 & $7-22$ & $9,29-$ \\
2 & (hari) & & & & 12,44 \\
& Berat & 1767,67 & 330,65 & $980-2400$ & $1644,2-$ \\
3 & Badan & & & & 1891,13 \\
& (gram) & & & & \\
\hline
\end{tabular}

Tabel diatas menunjukkan bahwa rerata usia gestasi bayi prematur yang dirawat di ruangan perinatologi RSUD Bangkinang adalah 31,70 dengan standar deviasi 2,25. Bayi premature mempunyai usia rerata 10,87 dengan standar deviasi 4,22. Berat badan bayi prematur menunjukkan rerata 1767,67 gram dengan standar deviasi 330,65.
b. Rerata Perubahan Suhu Tubuh Bayi Prematur Sebelum dan Sesudah dilakukan Terapi Sentuhan




\begin{tabular}{lllll}
\hline Variabel & & & & \\
& Std. & & \\
mean & Deviation & SE & N \\
\hline Sebelum & 36.0633 & 0.14735 & 0.2667 & 30 \\
& & & & \\
\hline & & & & \\
sesudah & 36,5867 & 0.1814 & 0.1690 & 30 \\
\hline
\end{tabular}

Dari tabel diatas dapat dilihat rerata suhu tubuh bayi prematur sebelum mendapat terapi sentuhan adalah 36,0633 dengan standar deviasi 0,14 sedangkan rerata suhu tubuh bayi prematur setelah diberikan terapi sentuhan adalah 36.5867 dengan standar deviasi 0,18.

\section{Analisa Bivariat}

Pengaruh Terapi Sentuhan Terhadap Peningkatan Suhu Tubuh Bayi Prematur yang dirawat di Ruangan Perinatologi di RSUD Bangkinang

\begin{tabular}{lllccc}
\hline Variabel & & $\begin{array}{l}\text { Std. } \\
\text { Deviation }\end{array}$ & $\begin{array}{c}\text { Min- } \\
\text { Max }\end{array}$ & $\begin{array}{c}\text { P } \\
\text { Value }\end{array}$ & $\mathrm{N}$ \\
\hline $\begin{array}{l}\text { Sebelum- } \\
\text { sesudah }\end{array}$ & 0.5233 & 0,1590 & $\begin{array}{c}0.5827 \\
-0.4639\end{array}$ & 0.000 & 30 \\
& & & & &
\end{tabular}

Berdasarkan tabel diatas dapat dilihat dilihat rerata suhu sebelum dan sesudah diberikan terapi sentuhan adalah sebesar 0,5233, dengan standar deviasi 0,15906 dengan nilai $\mathrm{P}=0,000$. Dengan demikian dapat disimpulkan ada pengaruh suhu tubuh bayi premature sebelum dan sesudah diberikan terapi sentuhan.

\section{PEMBAHASAN}

Sebelum dilakukan terapi sentuhan pada bayi prematur di ruang perinatalogi RSUD Bangkinang didapatkan nilai rerata suhu tubuh bayi premature adalah $36,0633^{\circ} \mathrm{C}$. hasil ini didukung oleh data yang di dapatkan bahwa bayi premature yang dirawat berada pada usia gestasi rata rata 31 minggu ketika dilahirkan.termoregulasi bayi yang normal itu akan terjadi jika bayi dilahirkan pada usia gestasi $37-$ 42 minggu. Setelah diberikan terapi sentuhan maka didapatkan rerata suhu tubuh bayi premature meningkat menjadi $36,5867^{\circ} \mathrm{C}$.

Bayi baru lahir terutama bayi premature dapat mengatur suhu tubuhnya, sehingga akan mengalami stress dengan adanya perubahan lingkungan dari dalam rahim ibu ke lingkungan luar yang suhunya lebih tinggi. Suhu dingin ini menyebabkan air ketuban menguap lewat kulit, pada lingkungan yang dingin, pembentukan suhu tanpa mekanisme menggigil merupakan usaha utama seorang bayi untuk mendapatkan kembali panas tubuhnya. Pembentukan suhu tanpa menggigil ini merupakan hasil penggunaan lemak coklat untuk produksi panas.Timbunan lemak coklat terdapat di seluruh tubuh dan mampu meningkatkan panas tubuh sampai $100 \%$. Untuk membakar lemak coklat, sering bayi harus menggunakan glukosa guna mendapatkan energi yang akan mengubah lemak menjadi panas. Lemak coklat tidak dapat diproduksi ulang oleh seorang BBL. Cadangan lemak coklat ini akan habis dalam waktu singkat dengan adanya stress dingin. Semakin lama usia kehamilan semakin banyak persediaan lemak coklat bayi.

Pada bayi baru lahir, akan memiliki mekanisme pengaturan suhu tubuh yang belum efisien dan masih lemah, sehingga penting untuk mempertahankan suhu tubuh agar tidak 
terjadi hipotermi. Proses kehilangan panas pada bayi dapat melalui proses konveksi, evaporasi, radiasi dan konduksi. Hal ini dapat dihindari bila bayi dilahirkan dalam lingkungan dengan suhu sekitar 25-28 0C, dikeringkan dan dibungkus dengan hangat.Simpanan lemak yang tersedia dapat digunakan sebagai produksi panas.

\section{Analisis dilakukan untuk} melihat adanya perbedaan antara sebelum dan sesudah dilakukan terapi sentuhan dan untuk melihat adanya pengaruh peningkatan suhu tubuh pada bayi prematur. Berdasarkan hasil analisis dapat disimpulkan bahwa rerata peningkatan suhu bayi prematur setelah dilakukan terapi sentuhan dengan suhu bayi premature sebelum mendapatkan terapi sentuhan 0,52333, dengan standar Deviasi adalah 0,15906 dengan nilai $\mathrm{p}=0,000)$. Dengan demikian dapat disimpulkan bahwa ada pengaruh terapi sentuhan terhadap peningkatan suhu tubuh pada bayi prematur yang dirawat di ruangan perinatologi RSUD Bangkinang.

Peningkatan suhu tubuh bayi prematur setelah mendapatkan terapi sentuhan disebabkan karena tindakan terapi sentuhan dapat melancarkan sirkulasi peredaran darah bayi prematur, kemudian adanya transfer suhu dari terapis ke bayi premature dan adanya perbaikan termoregulasi pengaturan suhu di otak bayi prematur (Diego, 2008).

Termoregulasi atau pengaturan suhu tubuh pada bayi baru lahir merupakan aspek yang sangat penting dan menantang dalam perawatan bayi baru lahir.Termoregulasi adalah keseimbangan antara kehilangan panas dan produksi panas tubuh. Tujuan utama adalah untuk mengontrol lingkungan neonatus dalam mempertahankan lingkungan suhu netral (neutral thermal environment) dan meminimalkan pengeluaran energi (Indrasanto,2008).

Adapun hasil penelitian ini menunjukkan peningkatan suhu tubuh bayi prematur setelah mendapatkan terapi sentuhan tidak begitu signifikan atau rerata peningkatan suhu tubuh hanya 0,5234. Berdasarkan hasil observasi hal ini disebabkan kondisi ruangan perawatan yang menggunakan AC sehingga membuat suhu dingin yang terjadi diluar incubator merembes masuk kedalam pintu incubator yang dibuka pada saat intervensi dilakukan dan ditambah lagi dengan kondisi tangan terapis dalam keadaan dingin kembali akibat suhu ruangan.

Suhu tubuh dapat mengalami pertukaran dengan lingkungan, artinya panas tubuh dapat hilang atau berkurang akibat lingkungan yang lebih dingin. Begitu juga sebaliknya, lingkungan dapat mempengaruhi suhu tubuh manusia.Perpindahan suhu antara manusia dan lingkungan terjadi sebagian besar melalui kulit (Mela Sari, 2014).

Penelitian ini sejalan dengan penelitian yang dilakukan Dieter (2003).Penelitian tersebut dilakukan dengan metode kuasi eksperimen untuk mengidentifikasi pengaruh terapi sentuhan terhadap peningkatan suhu tubuh dan berat badan. Penelitian ini dilakukan pada bayi premature dengan usia gestasi $25-34$ minggu didapatkan usia gestasi $31,1+$ 2,5 minggu.

Rerata usia gestasi bayi prematur dalam penelitian ini tidak jauh berbeda dengan yang dilakukan oleh peneliti yaitu 31,70 minggu 
dengan standar deviasi 2,25. Hasil penelitian ini didukung oleh teori yang dikemukakan Klauss dan Fanaroff (2003), bahwa usia gestasi bayi akan mempengaruhi tingkat kematangan pengaturan suhu bayi tersebut. Semakin tua usia gestasinya maka akan semakin matang semua organ tubuhnya termasuk timbunan lemak di bawah kulit dan mempengaruhi timbunan lemak coklat.

Pembentukan lemak coklat di mulai minggu ke-30. Lemak coklat yang cukup akan memudahkan bayi untuk mempertahankan suhu tubuhnya. Jaringan lemak merupakan isolator panas, pada bayi dengan lemak jaringan kulit yang banyak maka suhu tubuhnya tidak mudah dipengaruhi oleh suhu lingkungan sehingga bayi tersebut dapat mempertahankan suhu tubuhnya dengan baik (Klauss dan Fanaroff, 2003).

Sama halnya dengan berat badan bayi prematur dalam penelitian ini dengan 30 responden, menunjukkan berat badan bayi mulai 980 sampai 2400 gram dengan rerata 1767,67 gram. Penelitian ini sejalan dengan penelitian yang dilakukan oleh Dieter (2003) yaitu tindakan terapi sentuhan terhadap berat badan dan pola tidur. Responden penelitian ini dilakukan terhadap pada bayi premature dengan berat badan mulai 750 gram sampai 1600 gram.

Berat badan bayi prematur dalam penelitian ini agak sedikit berbeda dengan penelitian yang dilakukan sebelumnya. Peneliti berasumsi bahwa perbedaan ini dapat terjadi karena berat badan bayi premature dipengaruhi oleh usia gestasinya. Semakin besar usia gestasi bayi tersebut maka akan semakin tinggi berat badannya.
Hal ini didukung oleh penelitian yang telah dilakukan oleh Diego (2008), bahwa terapi sentuhan memberikan hasil yang positif terhadap perkembangan bayi seperti terhadap kenaikan berat badan, suhu tubuh, pola tidur dan penggunaan energi.

Manfaat dari terapi sentuhan ini sudah disadari oleh beberapa rumah sakit dalam merawat bayi prematur di ruang perinatologi.Namun demikian tindakan terapi sentuhan ini tetap harus dilakukan dengan hati-hati, dengan tidak memberikan rangsangan yang berlebihan.

\section{Kesimpulan}

Dari hasil penelitian dapat disimpulkan bahwa ada pengaruh terapi sentuhan terhadap peningkatan suhu tubuh pada bayi prematur yang dirawat di ruangan perinatologi RSUD Bangkinang.

\section{DAFTAR PUSTAKA}

Ariawan, I. (1998). Besar dan metoda sampel pada penelitian kesehatan. Jakarta: Fakultas Kesehaan Masyarakat Universitas Indonesia.

Basuki, B. (2000). Aplikasi metode kasus kontrol. Jakarta: Fakultas Kedokteran Universitas Indonesia.

Burns, N., \& Grove, S.K. (2003). Undangan nursing research. $\left(3^{\text {rd }}\right.$ edition). Philadelphia: W.B. Sounders Company.

Dahlan, M.S. (2010). Statistik untuk kedokteran dan kesehatan. Edisi 4. Jakarta: Salemba Medika.

Hastono, S.P. (2007).Analisis data kesehatan. Jakarta: Fakultas 
Kesehatan Masyarakat Universitas Indonesia.

Harrison, L., Wiliams A.K., Berbaum, M.L., Stem, J.T., Leeper, J., (2000). Effect of developmental, health status, and enviromental vaiable on praterm infants responses to a gentle of human touch intervention, Alabama: Johnson and Jhonson Institute.

Hurlock, E.B. (1999). Psikologi perkembangan:Suatu pendekatan sepanjangg rentang kehidupan. Edisi 5.(Dra.Istiwidayati \& Drs. Soedjarwo.Penerjemah). Jakarta: Penerbit Airlangga.

Indrasanto, E., dkk (2008). Pelayanan obsetri dan neonatal emegensi komprehensif (PONEK), Jakarta.

Klaus M.H., \& Fanarrof A.A. (2003).Penatalaksanaan neonatus resiko tinggi.Edisi I. (Dr. Dwikikusworo \& Dr. Endang, Penerjemah). Jakarta: EGC

Maryunani, A., \& Nurhayati. (2009). Asuhan kegawatdaruratan dan penyulit pada neonatus, Edisi I. Jakarta: CV. Trans Info Media.

Mohctar, P. (2004). Obsetri dan gynocologi.Edisi 5. Jakarta: EGC

Modrcin-McCarthy, M.A. (1996). The physiological and behavioral effect of a gentle human touch nursing intervention on preterm infant. Tennessee: University of tennessee.

Polit, D.F., \& Hungler, B.P. (2001).Nursing research:Prinsiples

and methods. ( $6^{\text {th }}$ edition). Philadelphia: Lippincott Williams \& Wilkins.

Roesli U., (2001).Pedoman pijat bayi prematur dan bayi usia 0-3 bulan.Edisi 1. Jakarta: Trubus Agriwidia.

Rudolph, A.M., Hoffman, J.I.E \& Rudolph C.D., (2006). Buku ajar pediatri Rudolph, Volume 1. (Samik Wahab, dkk. Penerjemah). Jakarta: EGC

Sastroasmoro, S., \& Ismael, S. (2002).Dasar-dasar metodologi penelitian klinis.Edisi 2. Jakarta: CV Sagung Seto.

Sastroasmoro, S. (2002).Pemilihan subyek penelitian, dalam Sastroasmoro, S., \& Ismael S., Dasar-dasar metodologi penelitian klinis (hal. 75).Edisi 2. Jakarta: CV Sagung Seto

Sugiyono, (2007).Metoda penelitian kuantitatif kualitatif dan $R \& D$. Bandung: CV ALFABETA

Tomey, A.M., \& Alligood, M.R. (2006).Nursing theorist and their works. $\left(6^{\text {th }}\right.$ edition). St. Louis: Mosby Inc.

Whaley \& Wong D.L. (2004).Nursing care of infant's and children. $\left(5^{\text {th }}\right.$ Edition, Missouri: Mosby Inc

Wong, D.L. (2004). Pedoman klinis keperawatan pediatrik.Edisi 4.(Monica Ester S.Kp. Penerjemah). Jakarta: EGC 